\title{
Epitaxial $\mathrm{TiO}_{2}$ Shell Grown by Atomic Layer Deposition on $\mathrm{ZnO}$ \\ Nanowires Using a Double-Step Process and Its Beneficial \\ Passivation Effect
}

Thomas Cossuet, ${ }^{1}$ Estelle Appert, ${ }^{1}$ Odette Chaix-Pluchery, ${ }^{1}$ Hervé Roussel, ${ }^{1}$ Laetitia Rapenne, ${ }^{1}$ Gilles Renou, ${ }^{2}$ Frédéric Sauvage, ${ }^{3}$ and Vincent Consonni. ${ }^{1 *}$

${ }^{1}$ Univ. Grenoble Alpes, CNRS, Grenoble INP, LMGP, F-38000 Grenoble, France

${ }^{2}$ Univ. Grenoble Alpes, CNRS, Grenoble INP, SIMaP, F-38000 Grenoble, France

${ }^{3}$ Laboratoire de Réactivité et Chimie des Solides, Université de Picardie Jules Verne, CNRS

UMR7314, 33 Rue St-Leu, 80039 Amiens cedex, France

*Corresponding Author: vincent.consonni@grenoble-inp.fr

\section{SUPPORTING INFORMATION}

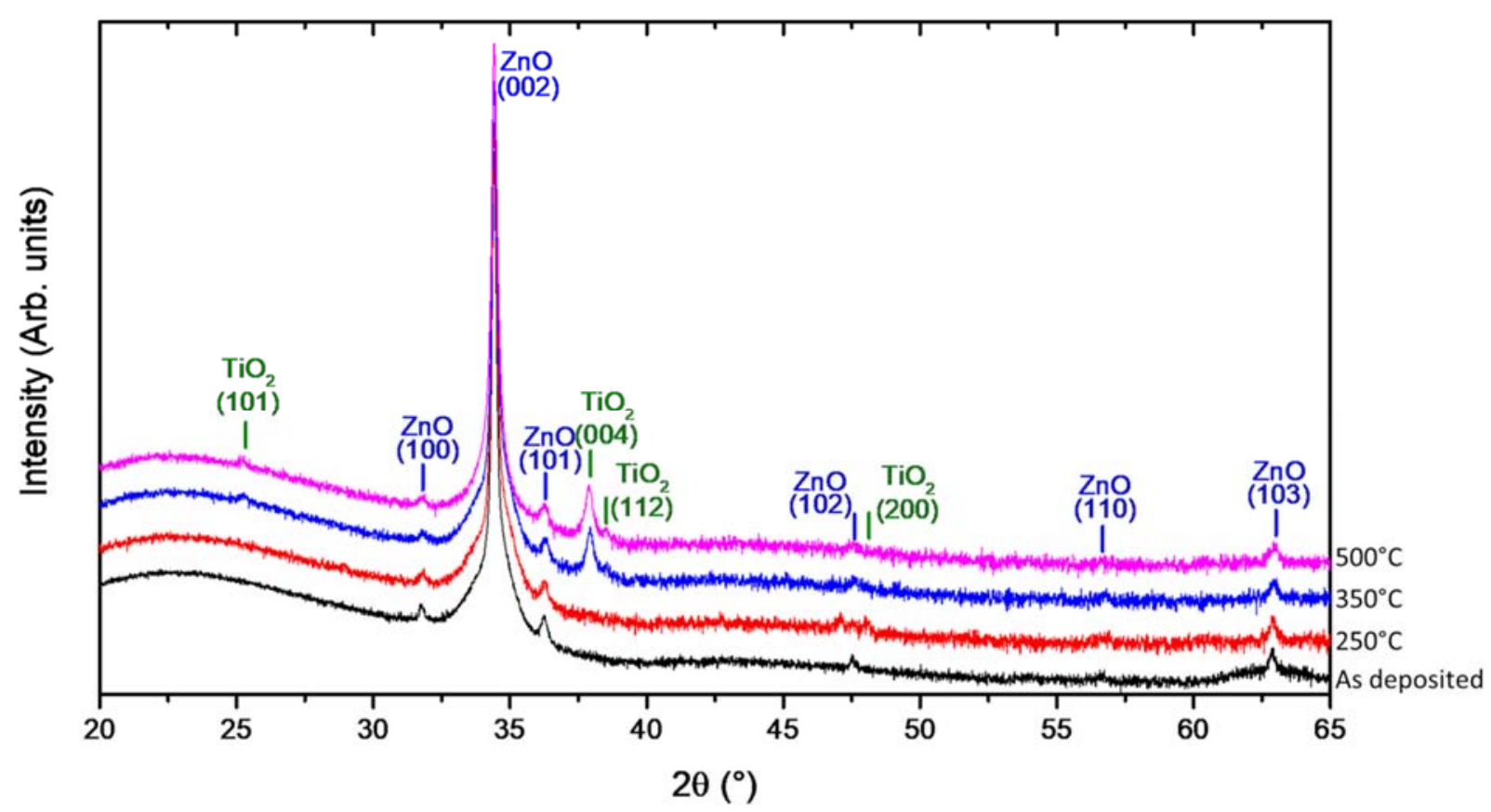

Figure S1. XRD pattern of as-deposited $\mathrm{ZnO} / \mathrm{TiO}_{\mathrm{x}}$ core-shell $\mathrm{NW}$ heterostructures and corresponding XRD patterns obtained after annealing at 250,350 and $500{ }^{\circ} \mathrm{C}$ for 3 hours in air. 


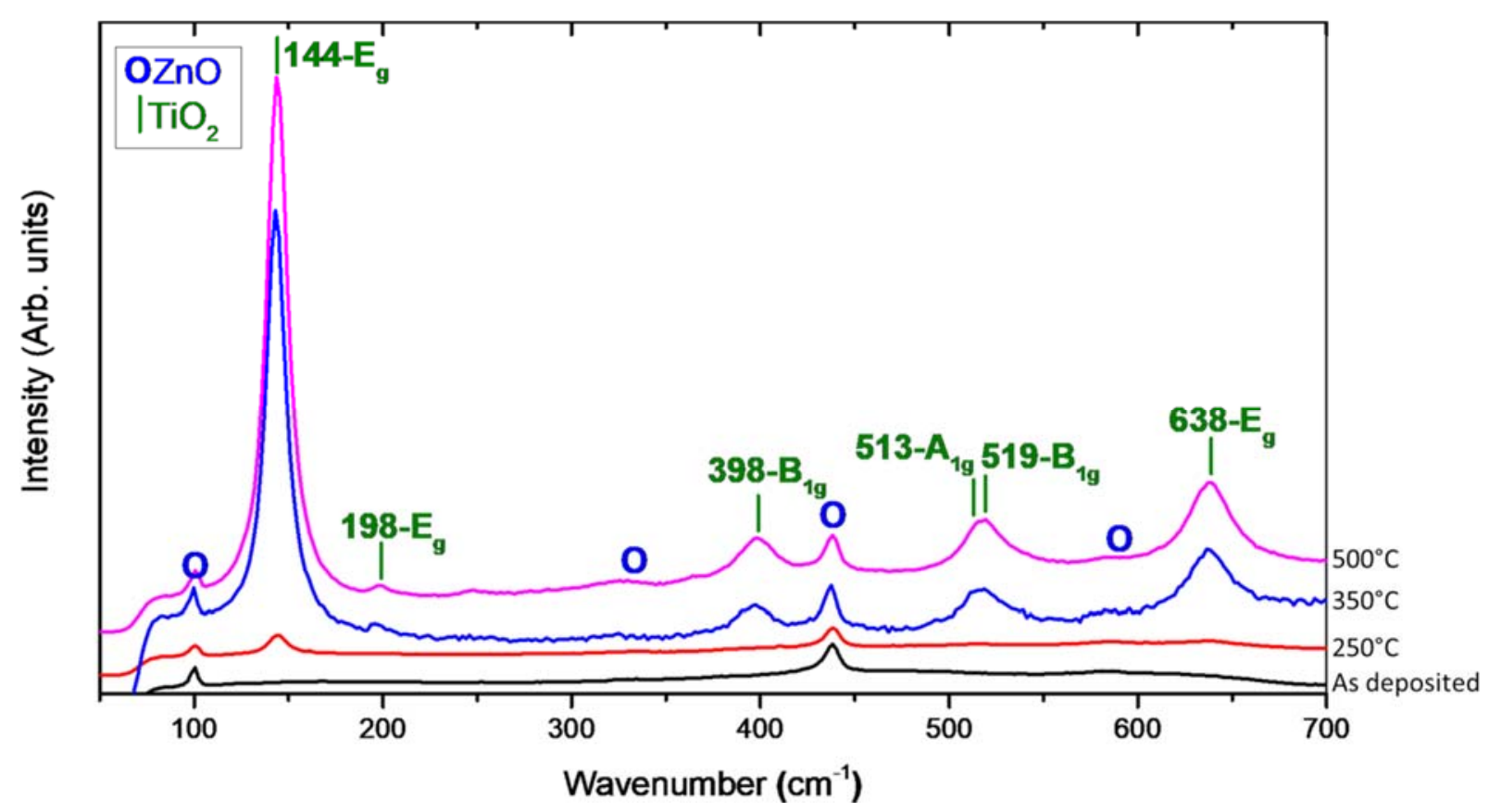

Figure S2. Raman spectrum of as-deposited $\mathrm{ZnO} / \mathrm{TiO}_{\mathrm{x}}$ core-shell $\mathrm{NW}$ heterostructures, and corresponding Raman spectra collected after annealing at 250,350 and $500{ }^{\circ} \mathrm{C}$ for 3 hours in air. 